\title{
Community Attitude towards Community Health Fund on Health Security in Kalambo District, Rukwa Region, Tanzania
}

\author{
Alexander D. Kasonso, \\ Department of Development Studies, College of Social Sciences and Humanities, \\ Sokoine University of Agriculture, P.O. Box, 3024, Morogoro, Tanzania
}

Emanuel E. Chingonikaya,

Department of Development Studies, College of Social Sciences and Humanities, Sokoine University of Agriculture, P.O. Box, 3024, Morogoro, Tanzania

\section{Anna N. Sikira}

Department of Development Studies, College of Social Sciences and Humanities, Sokoine University of Agriculture, P.O. Box, 3024, Morogoro, Tanzania

Received: April 19, 2020 Accepted: June 1, 2020 Online published: June 18, 2020 doi:10.5296/jpag.v10i2.17207

URL: https://doi.org/10.5296/jpag.v10i2.17207

\begin{abstract}
Community Health Fund (CHF) is one among health insurance schemes found in Tanzania. It was established in 1996 with the aim of improving the health of people who work in informal sectors. However, since its formulation, it has not performed well; the majority of HHs are not members, and some members are withdrawing from the scheme. The overall objective was to assess the attitude of community members towards the importance of CHF for health security. Specifically, the paper assesses the attitude towards CHF interventions among members and non-members of $\mathrm{CHF}$ and compares the attitude between members and non-members of CHF on health security. Cross sectional research design was used in this study. Simple random sampling technique using the lottery method was employed to select 354 respondents. Data were collected using a household questionnaire survey, Focus Group Discussions guide, Key Informant Interviews checklist and documents' reviews. Descriptive statistics, inferential statistics and content analysis were used to analyze the data. The findings show that CHF has inclusive benefits to its members as it covers costs of health
\end{abstract}


treatment rather than paying money every time they attend medical treatments. Furthermore, the attitude towards CHF among members and non-members was accounted for $9.3 \%$ and 51.9 negative, $2.3 \%$ and 4.1 neutral and 88.4 and 44.0 positive. This indicates that the majority of people in the study area had a positive attitude towards CHF services. Thus, the study concludes that a great proportion of members of CHF in Kalambo District have positive attitude towards CHF intervention while the majority of non-members have negative attitude towards CHF intervention because they were not aware of it due to lack of knowledge. It is recommended that the government should mainstream CHF intervention to all communities so that non-members can join the scheme and hence get better health services. Also, the study recommends that the CHF service providers should put more emphasis on sensitising communities against negative attitudes from non-members of $\mathrm{CHF}$.

Keywords: community attitude, community health, community health fund

\section{Introduction}

The Community Health Fund (CHF) is one of the social security funds found in Tanzania. Social security is the protection provided to individuals and households to ensure access to healthcare and to guarantee income security when the one concerned is in a position of income stoppage in case like sickness, injury at work place, maternity, invalidity, old age, unemployment, or loss of a breadwinner (ILO, 2018). Morestin (2009) reports that improvement of access to healthcare services is provided through health insurance schemes. Different countries have used different mechanisms on how they promote health security systems. Globally, there are sixteen countries that have promoted better healthcare systems (Martin, 2017). These are Luxembourg, Singapore, Switzerland, Netherlands, Sweden, Germany, Belgium, Newzealand, Norway, France (Europe), Hongkong, Japan (Asia), Israel, Qatar (Middle East), Australia, and Canada (North America). The experience shows that European countries promoted health care systems such that their people's life expectancies are relatively high compared to the rest of the countries in the world (Martin, 2017). The adoption of Community Health Insurance depends much on community attitudes on particular types of insurance as reported by Chingonikaya et al. (2018) that attitude may influence the behaviour change of someone as it is a relatively enduring organization of beliefs, and behavioural tendencies towards socially significant objects, groups, events or symbols.

In Sub Saharan Africa (SSA), negative attitudes have been a barrier towards health insurance membership (Carapinha et al., 2010). Households use savings, assets, procured loans or borrowings from family and friends to cope with high out-of-pocket payments (Carapinha et al., 2010). Approximately, 30\% of households in 15 SSA countries are financing their health care by borrowing or selling their assets (Carapinha et al., 2010). Out-of-pocket payments can lead to impoverishment when households do not have ability to pay. This can probably cause difficulties to households joining health insurance schemes. Rwanda was among the countries in SSA which were doing well in the Community Health Insurance Scheme since it was introduced in 1999 as mentioned by Chemouni B. (2018) that was doing well on Community Health Insurance (CHI). Some of the reasons for good performance were the 
people's positive perception on community health insurance schemes, members being invited in scheme's general assembly where they interact with the administrative councils of the scheme and discuss needs, concerns and suggestions for CHI improvements. In Tanzania, the Government was the major provider of health services from 1961 to 1991 under the socialist ideology (URT, 2008). Private healthcare services providers were actually banned in 1977 under the Private Hospitals (Regulation) Act (URT, 1977). In the 1990s, there were health sector reforms which started to improve the quality of health care services and introduced cost sharing of health services. CHF was introduced in 1996 and was piloted in Tabora Region, specifically in Igunga District, and later it was extended to other districts (Macha et al., 2015). In Kalambo District Council, CHF was introduced in 2012 after formulation of Kalambo District Council that formerly was a part of Sumbawanga District Council.

Different scholars have studied various attitudes of the people towards the CHF (Chatama, 2007; Ekman, 2004; Lekashingo, 2012; Turkson, 2009). On another side, constraints in operationalization of the funds have been found in different studies (Musau, 2004; Msuya et al., 2004; URT, 2006; Waheke, 2015), particularly contributions of the fund to community health security (Chee et al., 2002 and WHO, 2003). There is a negative attitude reported by Chatama (2007) that CHF members do wait longer to be attended at the health facilities as compared to non-members, but on another side, Ekman (2004) reported that non-CHF members perceived that CHF members were attended first before those paying user fees. However, it is not clear whether operationalization and policies governing CHF are positively impacted to the beneficiaries' satisfaction in the study area. The funds are still poorly operating; this probably requires other studies to be conducted as this study looks into the attitudes of the community towards the CHF which have been inadequately addressed by previous studies in Tanzania and particularly in the study area (Ekman, 2004; Turkson, 2009; Waheke, 2015; URT, 2006; WHO, 2003). The overall objective of this paper was to assess the attitude of community members towards the importance of CHF for health security in Kalambo District. Specifically, the paper aimed at assessing the attitude towards CHF interventions among members and non-members of CHF, comparing the attitude between members and non-members of CHF in the area of study and tested the hypothesis that attitudes towards $\mathrm{CHF}$ is not significantly different between beneficiaries and non-beneficiaries of $\mathrm{CHF}$ interventions.

In order for the fund to operate effectively, there is a need for active member-ship, good management and good health facilities (HPSS, 2018). Several studies that have been conducted show that some members are withdrawing from the scheme (Msuya et al., 2004; Mtei and Mulligan, 2007; Marwa et al., 2013). Despite the importance of CHF as it is described in CHF Act No.1 of 2001, this targets members to have access to reliable and effective health care by creating a sustainable financial mechanism (URT, 2001). Many studies have been conducted and come up with alternatives for strengthening various health security funds but they have not helped (Martin, 2017; WHO, 2015; URT, 2008; URT, 2003; Marwa et al., 2013). However, little information is available on community attitude towards CHF in the study area. Therefore, the study on which this paper is based conducted to bridge the research gap so as to inform various stakeholders such as Government officials, health 
sectors, policy makers, community members and non-members of CHF, NGOs, and Donors responsible for the same topic.

Theoretically, the study adopted a Social Cognitive Theory (SCT), (Bandura, 1997) as cited by Glanz et al. (2002). It tells about evaluating people's behavioural change, which depends on environment, people and behaviour, these factors are constantly influencing each other. People and behavior represent the situation in which members of the society live. Environment refers to the factors that can affect a person's behaviour; these are physical and social environment. For this study, SCT reflects how CHF members can acquire and maintain attitudes, be it positive or negative/accept or reject some ideas related to health service provision resulting to health security whenever imposed to them by health providers, where the majority of HHs in study area was found to be positive against CHF services. Social environment includes community relationships to $\mathrm{CHF}$, while physical environment includes distances from the households to places where health services are provided, household income and quality of health services. The situation refers to the cognitive or mental representations (people's perception) on health security that may affect a person's behaviour positively or negatively towards CHF.

Conceptually, the outcome shows that attitude which contains knowledge, awareness and perception of communities towards CHF health security influences the households' environments including social environment such as community relationship to $\mathrm{CHF}$, and physical environment like distance from household to health services providers, household income and quality of health services to CHF membership for health security. These outcomes which determine the health security, affect households behaviour positively or negatively towards CHF.

\section{Methodology}

The study on which this paper is based was conducted in Kalambo District Council. Kalambo is one among the four districts of Rukwa Region in Tanzania. It was officially established on $23^{\text {rd }}$ December 2012 as a result of split of the Sumbawanga District Council, and its administrative head quarter is Matai town. It is located in the Southern Highlands and lies between latitudes $8^{0} 54^{\prime}$ ' and $8^{0} 15^{\prime}$ 'South and longitudes between $31^{0} 12^{\prime}$ and $31^{\circ} 51^{\prime}$ East. The district is bordered by Zambia in the South and Songwe Region (Momba District) in the South-east. It also borders with Lake Tanganyika in the South-west, Nkasi District in the West, Sumbawanga District Council and Sumbawanga Municipal Council to the North. Kalambo District Council is estimated to have $4,715 \mathrm{~km}^{2}$, of which $504 \mathrm{~km}^{2}$ is water and $4,211 \mathrm{~km}^{2}$ is land area. The reason for choosing Kalambo District was based on economic activities whereby the majority of dwellers are employed in informal sector which is the main target of CHF for its coverage (URT, 2004). The main economic activities are crop farming, livestock keeping, fishing, trading and bee keeping. Also, Kalambo District is one among districts with few CHF numbers basing on HSSP III targets as well as one among districts in Rukwa Region where only $7.5 \%$ of the population is covered, while in Singida Region $54.4 \%$ are covered and in Mbeya Region, 43.0\% are covered with the CHF (UTR, 2015).

The study employed a cross-sectional research design in order to collect multiple cases in a 
single point of time (Bailey, 1998). The design is considered to be appropriate to provide an image of the current situation in a specific time (Ellsberge and Heise, 2005). Five (5) wards were targeted whereby in each ward one village was purposively selected based on potentiality in respective economic activitties (URT, 2004). The selected wards and villages were Msanzi (Msanzi Kati village), Matai (Singiwe village), Mkowe (Mbuza village), Kisumba (Kasote village) and Kasanga (Kasang village) their economic activities were crop farming, trading, livestock keeping, bee keeping and fishing activities. The population of the study were members and non-members of CHF. The unit of analysis was a household, and the sampling unit for this study was a household head for CHF members and non-members. Each village had varied numbers of members and non-members of CHF (Table 1.0). The sampling frame for members of CHF was obtained from a list of names registered at the dispensary of each village with the assistance of a clinical officer. While for non-members the sampling frame was a list of names of all households at 5 villages obtained with the assistance of village leaders. Simple random sampling by using the lottery method was used to select the sample from the lists of names selected from each village. The sample size was 354 respondents. 86 respondents were members of CHF interventions and 268 were non-members. This was based to the fact that CHF members were very few as compared to non-members in the study area (Table 1.0). The sample size was determined by using Yamane`s (1973) as cited by Israel (2013) as follows

$n=\frac{N}{1+N(e)^{2}}$

$$
=3060 / 1+3060(0.05)^{2}=354
$$

Where: $\mathrm{n}$ is the sample size, and $\mathrm{N}$ is the population. In this study, $\mathrm{N}$ was the estimated number of households in five selected villages. Since there were few CHF members while the great interest of the research was in them, simple stratified sampling was used to select equal numbers of $\mathrm{CHF}$ members and non-members.

Table 1. Number of sampled households in each study village

\begin{tabular}{llrrrr}
\hline Ward & Village & Total & Sampled households & CHF members & CHF non-members \\
& & households (n) & $(\mathbf{n})$ & \\
\hline Msanzi & Msanzi kati & 599 & $599 / 3060 * 354=69$ & 20 & 49 \\
Matai & Singiwe & 300 & $300 / 3060 * 354=35$ & 8 & 27 \\
Mkowe & Mbuza & 564 & $564 / 3060 * 354=65$ & 11 & 54 \\
Kisumba & Kasote & 500 & $500 / 3060 * 354=58$ & 14 & 44 \\
Kasanga & Kasanga & 1097 & $1097 / 3060 * 354=127$ & 33 & 94 \\
Total & & $\mathbf{3 0 6 0}$ & $\mathbf{3 5 4}$ & $\mathbf{8 6}$ & $\mathbf{2 6 8}$ \\
\hline
\end{tabular}

Data collection involved primary data; a questionnaire survey was used to collect data from the respondents. The types of information that were targeted here were based on community's 
perceptions towards CHF. Key Informant Interviews (KIIs) and Focus Group Discussions (FGDs) were used as the main methods for collecting qualitative data. A checklist was used to gather information from KIIs which involved those who worked with CHF such as District Commissioner (DC), District Medical Officer (DMO), Clinical Officers (COs), Nurses, Ward Executive Officers (WEOs), Ward Community Development Officers and Village Executive Officers (VEOs). The type of information that was collected in this method was based on $\mathrm{HHs}$ levels of awareness concerning the existence of CHF. A focus group interview guide was used in discussion to gather information from 6-12 FGDs participants which in each discussion session. A total of ten FGDs were conducted in the study area. The gathered information was used to provide additional and detailed community's attitude towards CHF. Participants who were considered in FGDs were those who worked in informal sectors which are the targeted group of CHF. Gender balance was another factor that was considered for FGDs whereby equal numbers of men and women were selected. Qualitative data were analysed using content analysis approach. These are data obtained from FGDs and KIIs. Therefore, by means of content analysis method, the data collected through verbal discussions were analysed in details whereby recorded discussions were broken down into smallest meaningful units of information.

Attitude of community members towards CHF was measured by using a Likert scale. Statements with positive and negative connotations were formulated and included in the questionnaire. Respondents' responses were recorded as strongly agree, agree, undecided, disagree and strongly disagree. The scale has been found to be an effective technique for the measurement of attitudes (Likert, 1932). The five (5) - points Likert scale were assigned numbers as follows: $(5=$ strongly agree, $4=$ agree, $3=$ undecided, $2=$ disagree and $1=$ strongly disagree). The responses from all the statements were combined to create a measurement of an Attitudinal Scale (AS). The AS is a single variable used to represent cumulative perception of attitude (Likert, 1932). Statements favourable to the construct were positively worded, while unfavourable statements used negative connotation. Then numerical values for the response's options were reversed when calculating the overall score. Higher values indicated positive attitude disposition of favourably attitude towards CHF, implying that the respondent was supporting CHF interventions. While low values indicated negative attitude (i.e. unfavourable response) towards CHF, implying that the respondents were not supporting CHF interventions.

The overall scores on the Likert scale were categorized into positive, neutral and negative attitudes of community members towards CHF. The highest possible score was calculated by multiplying 18 statements by 5 points to get 90 points, while the middle point was calculated by multiplying 18 statements by 3 points to get 54 points, and the lowest possible score was calculated by multiplying 18 statements by 1 point to get 18 points. Therefore, 54 was the cut-off point and stood for neutral attitude. Hence, scores from 18 to 53 on the overall scores were considered as negative attitude, while 55 to 90 stood for positive attitude.

A Mann Whitney $U$ test was used to test the hypothesis that attitudes towards CHF against local community members are significantly different between members and non-members of CHF interventions $(p<0.05)$. The test was ideal because the technique is appropriate to test 
for differences between two independent groups (Pallant, 2007). The test is the alternative of the t-test for independent samples and also it analyses differences in the positions of ordinal dependent variables in two independent groups (Nachar, 2008).

\section{Results and Discussion}

The findings presented in Table 2 indicate respondents' opinions about the importance of a Community Health Fund (CHF) for health security. Respondents were required to show their attitude towards CHF by indicating their degree of agreement with 18 statements about CHF intervention in the area of study. The majority of the respondents (in which $90.7 \%$ of members and $43.3 \%$ of non-members of CHF) agreed with the statement that CHF have comprehensive benefit package to its members. The results are in line with the CHF Act No. 1 of 2001 which targeted the health improvements to CHF members (URT 2001). On the other side, the majority of respondents $(66.3 \%$ members and $41.8 \%$ non-members of CHF) agreed on the statement that there is a minimum payment out of pocket for health services expenditure to $\mathrm{CHF}$ members. These findings imply that $\mathrm{CHF}$ has wide-ranging benefits to its members in relation to health issues since the health aspect is a core component of human capital and assists to cover health treatment in time a member has no money. This is similar to findings of a study by Mulupi et al. (2013) who studied on community perceptions of health insurance and their preferred design features: implications for the design of universal health coverage reforms in Kenyans where by it was found that people preferred a comprehensive benefit package that included inpatient and outpatient care with no co-payments.

Table 2. Respondents`attitudes toward CHF heath security $(\mathrm{n}=354)$

\begin{tabular}{|c|c|c|c|c|c|c|}
\hline \multirow[t]{2}{*}{ Statements } & \multicolumn{2}{|c|}{ Disagree (\%) } & \multicolumn{2}{|c|}{ Neutral $(\%)$} & \multicolumn{2}{|c|}{ Agree (\%) } \\
\hline & M & $\mathbf{N}-\mathbf{M}$ & $\mathbf{M}$ & $\mathbf{N}-\mathbf{M}$ & $\mathbf{M}$ & $\mathbf{N}-\mathbf{M}$ \\
\hline CHF has a comprehensive benefit package to its members & 8.1 & 15.3 & 1.2 & 41.4 & 90.7 & 43.3 \\
\hline $\begin{array}{l}\text { CHF supplies enough medicine to its members according to } \\
\text { requirements }\end{array}$ & 32.6 & 26.9 & 5.8 & 33.2 & 61.6 & 39.9 \\
\hline There is lack of choice for health services to CHF members & 41.9 & 38.8 & 3.5 & 35.1 & 54.7 & 26.1 \\
\hline $\begin{array}{l}\text { There is a minimum payment out of pocket for health services } \\
\text { expenditure to CHF members }\end{array}$ & 29.1 & 32.1 & 4.7 & 26.1 & 66.3 & 41.8 \\
\hline $\begin{array}{l}\text { CHF increases accessibility of health services to the } \\
\text { individuals }\end{array}$ & 10.5 & 34.0 & 0.0 & 36.2 & 89.5 & 29.9 \\
\hline CHF helps to improve the quality of the health services & 14.0 & 31.7 & 2.3 & 36.9 & 83.7 & 31.3 \\
\hline $\begin{array}{l}\text { CHF is just a means for its planners to steal money from poor } \\
\text { people }\end{array}$ & 62.8 & 48.1 & 15.1 & 34.7 & 22.1 & 17.2 \\
\hline $\begin{array}{l}\text { People paying user fees have better access to health services in } \\
\text { their areas }\end{array}$ & 11.6 & 29.1 & 8.1 & 36.2 & 80.2 & 34.7 \\
\hline People paying user fees are more satisfied with the care given & 12.8 & 30.2 & 4.7 & 33.6 & 82.6 & 36.2 \\
\hline People paying user fees have better health outcome & 11.6 & 29.9 & 1.2 & 37.7 & 87.2 & 32.5 \\
\hline CHF provides assurance of health services when one gets sick & 10.5 & 25.7 & 2.3 & 32.1 & 87.2 & 4.2 \\
\hline $\begin{array}{l}\text { CHF members enjoy quality services compared to } \\
\text { non-members }\end{array}$ & 8.1 & 26.1 & 22.1 & 39.9 & 69.8 & 34.0 \\
\hline
\end{tabular}


CHF members have better relationship with health care $\begin{array}{lllllll}5.8 & 23.5 & 14.0 & 36.6 & 80.2 & 39.9\end{array}$ providers

\begin{tabular}{|c|c|c|c|c|c|c|}
\hline $\begin{array}{l}\text { CHF is for the poor and those working in rural areas and/ or } \\
\text { the informal sector }\end{array}$ & 4.7 & 7.5 & 4.7 & 13.4 & 90.7 & 79.1 \\
\hline People drop from CHF because it's too costly & 40.7 & 27.6 & 20.9 & 25.0 & 38.4 & 47.4 \\
\hline $\begin{array}{l}\text { People are not interested in CHF because once they get sick, } \\
\text { they are cured with local medicine }\end{array}$ & 62.8 & 81.3 & 27.9 & 14.9 & 9.3 & 3.7 \\
\hline $\begin{array}{l}\text { People are not interested in CHF because once they get sick, } \\
\text { they are cured by faith and prayers. }\end{array}$ & 64.0 & 82.5 & 29.1 & 14.2 & 7.0 & 3.4 \\
\hline $\begin{array}{l}\text { People are satisfied with the health services which are funded } \\
\text { by CHF }\end{array}$ & 8.1 & 16.8 & 5.8 & 43.7 & 86.0 & 39.6 \\
\hline
\end{tabular}

Note: Figures in (\%) represent respondent's opinion, $\mathrm{M}=$ member of $\mathrm{CHF}, \mathrm{N}-\mathrm{M}=$ Non-member of $\mathrm{CHF}$

However, from FGD at Kasote village it argued that:

...having access to health services through CHF has many benefits including giving women ample time to do other activities as they are enabled to take care of sick people... (FGD at Kasote Village, $17^{\text {th }}$ December, 2018).

This finding indicates that, because women are assigned the role of taking care of sick people, children and elderly, then being secured to health services through CHF means it facilitates the role taken by women and therefore they will not be involved in such role; instead they will engage themselves in other activites such as enterpeneurship. The study findings, also, revealed that the majority of respondents (61.6\% of members and $39.9 \%$ of non-members) agreed with the statement that CHF supplies enough medicine to its members according to requirements. Also, $54.7 \%$ of members and $26.1 \%$ of non-members agreed that there is lack of choice for health services to CHF members. This was evidenced in KIIs at Kasanga village who said:

"...The challenge we are facing as CHF members is the limitations of health services by CHF card; we are allowed to use it at only one dispensary which is found in our village. If it happens there is no medicine, the card cannot assist to acquire such medicine from the any other dispensary..." (KIIs at Kasanga Village, $18^{\text {th }}$ December 2018).

Furthermore, the results show that majority of respondents $(89.5 \%$ of members and $29.9 \%$ of non-members) agreed on the statement that CHF increases accessibility of health services to individuals beacause even if it happen that there is no medicine at the dispensary, atleast sick people do get advice from clinical officers on sickness concerned. Likewise, for the statement which stated that CHF helps to improve the quality of the health services, the majority of the respondents (83.7\% of members and $31.3 \%$ of non-members) agreed.

The findings indicate that the majority of the respondents $(80.2 \%$ of members and $34.7 \%$ of non-members) agreed with the statement that people paying user fees have better access to health services in their areas. On the other hand, the majority of the respondents $(82.6 \%$ of members and $36.2 \%$ of non-members) agreed with the statement that people paying user fees 
are more satisfied with the care given; particularly on that, the majority of the respondents (87.2\% of members and $32.5 \%$ of non-members) agreed with the statement that people paying user fees have better health outcomes. This is because people paying user fees are not CHF members; therefore, they are free to get health treatment at any dispensary, be it private or public as they pay direct from the pockets. This is in line with a study by Chatama (2007), who reported that $\mathrm{CHF}$ members do wait longer to be attended at health facilities as compared to non-members because non-members can shift to other health facilities while CHF members are limited to particular dispensaries. This was also evidenced in an FGD at Singiwe Village the participants agree as follows:

... In order to get good health services, money is more important than CHF membership, because, with money you can access health services wherever you get sick, while with a CHF card, you must go to the dispensary that you were registered for, in order to be treated... (FGD at Singiwe Village, $13^{\text {th }}$ December, 2018).

The study results indicate that the majority of the respondents $(87.2 \%$ of members and $4.2 \%$ of non-members) agreed with the statement that $\mathrm{CHF}$ provides assurance of health services when one get sick. This is supported by information from an FGD at Mbuza village which was provided by FGD discussants that:

...The health services which we get together with our dependents as supported by CHF are better with less cost. One day when our fellow and his son were sick they used a CHF card to get medical treatment rather than using money from his pocket. This has motivated us to renew our CHF membership... (Mbuza village, FGD on, $11^{\text {th }}$ December, 2018).

This qualitative information indicates that beneficiaries of the scheme are motivated to use the CHF services. This implies that CHF members who have already benefited from the scheme are much aware of $\mathrm{CHF}$ health services as compared to non-members, and they are likely to renew their membership after its expiry.

The results indicated that the majority of the respondents $(69.8 \%$ of members and $34.0 \%$ of non-members) agreed with the statement which stated that CHF members enjoy quality services compared to non-members. This is in line with a study by Ekman (2004) who reported that non-CHF members perceived that CHF members were attended first before those who were paying user fees. The results indicate that the majority of respondents $(80.2 \%$ of members and $39.9 \%$ of non-members) agreed with the statement that CHF members have better relationship with health care providers, and $90.7 \%$ of members and $79.1 \%$ of non-members respondents agreed with the statement that $\mathrm{CHF}$ is for the poor and those working in rural areas and/ or the informal sector. This was supported by one key informant at Mbuza village who said that:

"... The majority of CHF members are poor people who cannot manage the costs of taravelling to Sumbawanga for treatments. That is why when rich people get sick normally go to Sumbawanga town for health services..." (KII at Mbuza village Dispensary, on $13^{\text {th }}$ December, 2018). 
Furthermore, the findings show that the majority of the respondents $(62.8 \%$ of members and $48.1 \%$ of non-members) disagreed with the statement that, CHF is just a means for its planners to steal money from poor people, and $62.8 \%$ of members and $81.3 \%$ of non-members disagreed with the statement that people are not interested in CHF because once they get sick they are cured by local medicines, Also, $64.0 \%$ of members and $82.5 \%$ of non-members disagreed with the statement that people are not interested in CHF because once they get sick they are cured by their faith and prayers. These statements were constructed in an unfavourable approach; therefore, disagreeing them means they turn into favourable statements. In so doing, these findings indicate that CHF is not a means for its planners to steal money for poor people. People are interested with CHF because once they get sick, they are not cured by local medicine. Lastly, people are interested in CHF because once they get sick, they are not cured by only faith and prayers. This implies that people in the study area have a trust in CHF health security provision. Studies conducted by Waheke, (2015), Kajala (2015), and Winani (2015), found that the majority of people who joined CHF didnot believe in traditional healing. In line with this, information from FGDs from Kasanga villages revealed that:

...Since we joined CHF we have been cured by medicine from dispensaries. If it happens there is no medicine at least we do get advice from clinical officers on where we can go for further solution of that case instead of going to witch doctors... (FGD at Kasanga villages, $18^{\text {th }}$ December, 2018).

\subsection{General Attitude of Respondents Towards the Importance of CHF on Health Security}

The study findings indicated that the overall attitude of community members about the importance of a CHF for health security was positive among members of CHF $(88.37 \%)$ while among non-members attitude towards CHF was negative (51.87\%) (Table 3.) These results indicate that the majority of members of CHF upheld positive attitude towards $\mathrm{CHF}$ interventions compared to their counterparts. The differences in attitude between members and non-members of $\mathrm{CHF}$ interventions could be a result of initiatives done by the government, CHF service providers and dispensaries (through their staff) via dissemination of information about the importance of CHF to members. On the other hand, negative attitude among non-members could have been contributed by their unawareness and lack of information on CHF. These findings imply that health services have proved success among CHF members, and non-members see it as worthless because they are unaware about the importance of CHF for the security of their health. Similar to this study findings, Jembere (2018) who researched on attitude of rural households towards Community Based Health Insurance (CBHI) in Northeast Ethiopia, the Case of Tehuledere District found that the majority of households had positive attitude towards CBHI scheme. Also, other scholars have found that community members who are registered to CHF tend to realize more benefits compared to unregisterd ones (Chatama, 2007; Lekashingo, 2012). Moreover, Kivelege (2015) who conducted his study in Morogoro District on Community Health Fund and Quality Health Services found similar results that the majority (50.8\%) of non-members of CHF had unfavourable attitude towards CHF interventions. 
Table 3. Overall Scores of attitude level for CHF members and non-members

\begin{tabular}{|c|c|c|c|c|c|c|}
\hline \multirow[t]{2}{*}{ Level of scores } & \multicolumn{2}{|c|}{ CHF members } & \multicolumn{2}{|c|}{ CHF Non-members } & \multicolumn{2}{|r|}{ Total } \\
\hline & $\mathbf{n}$ & $\%$ & $\mathbf{n}$ & $\%$ & $\mathbf{N}$ & $\%$ \\
\hline Negative $18-53$ & 8 & 9.3 & 139 & 51.87 & 147 & 41.53 \\
\hline Neutral 54 & 2 & 2.33 & 11 & 4.1 & 13 & 3.67 \\
\hline Positive 55-90 & 76 & 88.37 & 118 & 44.03 & 194 & 54.8 \\
\hline Total & 86 & 100 & 268 & 100 & 354 & 100 \\
\hline
\end{tabular}

Likewise, participants from FGDs in Mbuza and Kasote villages pointed out that members of CHF get more health secures in comparison to non-members; they agreed as follows:

...members of CHF have more access to health services and therefore have more health security than non-members of CHF ... (FGD at Mbuza and Kasote villages, $14^{\text {th }}$ and $17^{\text {th }}$ December, 2018).

This finding has an implication to CHF service providers on changing perception of community towards CHF interventions. Members of CHF become much aware on the benefits provided by CHF because they are closely attached to the services while it is difficult for non-members to know about CHF as they do not get any benefits from the fund. Ndomba et al. (2019) argued that majority of people who were not CHF members were not well aware with the benefits of the scheme.

\subsection{Differences in Respondents`Attitude Towards CHF Among Members and Non-Members of $\mathrm{CHF}$}

Mann-Whitney U test was conducted to test the difference in attitude towards CHF between members and non-members of CHF interventions. The results revealed significant $(\mathrm{p}<0.05)$ difference in mean rank scores of 238.02 and 158.02 report also the Mann-Whitney U coefficient for members and non-members of CHF interventions respectively (Table 4). Thus the hypothesis that members and non-members of CHF interventions are likely to differ in their attitude towards CHF is confirmed.

Table 4. Community attitude towards CHF members and non-members on CHF health security $(n=354)$

\begin{tabular}{lrrrrr}
\hline Respondents & $\mathbf{n}$ & Mean rank & Mann-Whitney $\mathbf{U}$ & $\mathbf{Z}$ & p-Value \\
\hline Members & 86 & 238.02 & 6319.000 & -7.213 & 0.000 \\
Non-members & 268 & 158.02 & & & \\
\hline
\end{tabular}

Higher mean ranks for members of CHF interventions signify respondents' positive attitude towards wrong myths that favour non-members towards CHF interventions (Table 4). This was evidenced by all FGDs in the study area when it came to the point of discussion on the 
impact of CHF health services to its members; the arguments were that it is performing well, a point which was supported by both members and non-members of CHF. In Kasanga village, one household head supported the point by saying that:

“...I'm not a CHF member due to financial problems, but the benefits that are in CHF package are well known to me, and any time if I will get money for CHF contribution, I will do so..." (household head at Kasanga villages, $18^{\text {th }}$ December, 2018).

The qualitative information above proves that some of people in the study area are aware of the CHF existence. One of the main reasons for not being members is lack of income for contributing to CHF so that they can qualify to be members. This is in line with URT (2001) which states that households to qualify for CHF should contribute the amounts that have been arranged by district councils concerned. On the other side, one key informant from Singiwe village, while supporting the point above, said:

“... some of people at this village are aware of CHF existence and would like to be members because they know the benefits of it, but the barrier is financial problems. So, they do ask if possible, to make contributions of valuable things like maize, or beans, or eggs and other things instead of cash payments, in order to qualify for the membership. These suggestions were submitted to officials concerned, but the answers delayed until today..." (KII at Singiwe village, on, $13^{\text {th }}$ December, 2018).

The qualitative statement above justifies the demand of CHF to targeted groups of people who work in the informal sector. They have introduced a number of alternatives that can qualify them for membership. This reflects findings of a study by Chee et al. (2002) which revealed that $\mathrm{CHF}$ is important for local community health security that majority of them are low income earners and are most vulnerable to diseases. Then, Government should extend valuable items like crops in regions that depends them as a product of their main economic activities to be contributed instead of money in the study area.

\section{Conclusions and Recommendations}

The study concludes that the majority of households in the study area are not CHF members as members and non-members were $24.3 \%$ and $75.7 \%$ respectively. This is due to lack of awareness of CHF existence and lack of money for contributing to CHF membership. Though, from these points, a greater proportion of members of CHF had positive attitude towards CHF health security while majority of non-members had negative attitude on that. It is also concluded that, there is a great number of non-members of CHF as compared to Members. This indicates that majority of households in study area are not aware of the existence of CHF. As a result, they have positive attitude to CHF because already they know and enjoy the benefits of it. On other side, non-members had negative attitudes on CHF as they had never engaged with CHF to observe its benefits. It is further concluded that institutions in forcing CHF policy have not played well their role that can result into increasing awareness of CHF existence to targeted communities which may increase the number of CHF members.

Thus, this study recommends that the government of Tanzania should mainstream CHF 
intervention to all communities so that many people can benefit from the health services and hence be health secures. It is also recommended that, contributions of valuable things that are owned by people in the study area like maize, beans and other crops should be accepted as payment for the CHF membership because the majority of people in the study area are farmers. CHF service providers should put more emphasis on sensitising communities about existing wrong attitude that exists from non-members of $\mathrm{CHF}$ which causes it not to be accepted. Furthermore, the study recommends that institutions, in forcing the CHF policy, should lay down strategies for creating awareness for the majority of households to join CHF. Furthermore, studies need to be conducted with this topic in order to capture comparative information from areas where $\mathrm{CHF}$ is operating poorly to those where is operating well because, this study was done in one area. Finally, the study recommends that there is a need for other studies questionnaire to be filled by most of female in households, because they are the ones who take duty of caring sick people in the family, they may tell what is needed for CHF improvements.

\section{Acknowledgements}

The authors gratefully acknowledge the Almighty God for the gift of good health during all moments of the study. We would like also to genuinely thank Sokoine University of Agriculture for granting research permit to undertake this study successfully. We extend our acknowledgements to Kalambo District Council Officials who were involved in this study like District commissioner (DC), District Executive officers (DED), and District Medical Officer (DMO). Also we acknowledge Ward Executive Officers, Village Executive Officers, and Clinical Officers from the study area. Finally, we give a lot of thanks to those members who participated in FGDs as well as HHHs who were concerned for the cooperation that they showed during data collection.

\section{References}

Bailey, D. K. (1998). Methods of Social Science Research. The free Press Collier Macmillan Publisher, London. 345pp.

Carapinha, J. L., Ross-Degnan, D., Dester, A. T., \& Wagner, A. K. (2010). Health Insurance System in Five Sub Saharan African Countries. In: Medicine benefits and data for decision-making. Article in press: 10pp.

Chatama, D. (2007). Community Health Fund in Tanzania, Predictors of and Barriers to Enrolment, South Africa. Dissertation for award of MA degree at Cape Town University. 22pp.

Chee, G., \& Smith, K. (2002). Assessment of the Community Health Fund in Hanang District, Tanzania. Abt associated Inc: 106 pp.

Chemouni, B. (2018). The political path to Universal Health Coverage: Power, ideas and community-based health insurance in Rwanda. https://www.sciencedirect.com/science/article/pii/S0305750X18300330. Site visited 14th March 2020 


\section{Macrothink}

Journal of Public Administration and Governance

ISSN 2161-7104

2020, Vol. 10, No. 2

Chingonikaya, E. E., \& Salehe, F. S. (2018). Attitudes of community towards female genital multilation in Manyoni District, Singida Region Tanzania. Journal of Education, Society and Behavioural Science, 25(1), 1-11.

Ellsberge, M., \& Heise, L. (2005). Researching violence against women. A Practical Guide for Researchers and Activist. World Health Organization and Programme for Appropriate Technology in Health (PATH). Washington DC. United State, 259pp.

Ekman, B. (2004). Community-based health insurance in low-income countries: a systematic review of the evidence. Health Policy Plan, 19(5), 249-270.

Glanz, K., Rimer, B. K., \& Lewis, F. M. (2002). Health Behavior and Health Education. Theory, Research and Practice. San Fransisco: Wiley \& Sons.

HPSS. (2018). Health Promotion and System Strengthening [https://www.eda.admin.ch/dam/countries/countries content/Tanzania/en/HPSS_Factsheet_EN.pdf] Site visited 13/04/2018.

ILO. (2018). International Labour Standards on Social security [https://www.ilo.org/global/standards/subjects-covered-by-international-labour-standards/soci al-security/lang--en/index.htm] Site visited 26/9/2018.

Israel, D. G. (2013). Determining Sample Size. University of Florida, IFAS Extension, PEOD6, United States of America, 5pp.

Jembere, M. Y. (2018). Attitude of Rural Households towards Community Based Health Insurance in Northeast Ethiopia, the Case of Tehuledere District. Prim Health Care, 8(3), 1-6.

Kajala, V. (2015). Community Health Fund Enrolment Determinants The Case Of Mvomero District. A Dissertation Submitted in Partial Fulfillment of the Requirements for Award of the Degree of Master in Health Systems Management of Mzumbe University. 47pp.

Kivelege, G. (2015). Community Health Fund and Quality Health Services in Morogoro District, Tanzania. A Dissertation Submitted in Partial Fulfilment of the Requirement for the Degree of Master of Arts in Rural Development of Sokoine University of Agriculture. Morogoro, Tanzania. 55pp.

Lekashingo, D. (2012). Exploring the effects of user fees, quality of care and utilization of health services on enrolment in community health fund, Tanzania. Dissertation for award of M.A degree at Muhimbili University.45 pp.

Likert, R. (1932). A technique for the measurement of attitudes. Archives of Psychology 22(140), 1-55.

Macha, J., Harris, B., \& Garshong, B. (2012). Factors influencing the burden of health care financing and the distribution of health care benefits in Ghana, Tanzania and South Africa. Health Policy and Planning, 27(1), 146-154.

Marwa, B., Njau, B., Kessy, J., \& Mushi, D. (2013). Feasibility of introducing compulsory community health fund in low resource countries: views from the communities in Liwale 
district of Tanzania. 298pp.

Mtei, G., \& Mulligan, J. (2007). Community Health Funds in Tanzania: A Literature review. Ifakara Health Research and Development Centre/Consortium for Research on Equitable Health System (CREHS), London: 15pp.

Mubyazi, G. M. (2004). East African Journal of public health: The Tanzania policy on health care fee waivers and exemption in practice as compared with other developing countries: Evidence from recent local studies and international literature: 10pp.

Mulupi, S., Kirigia, D., \& Chuma, J. (2013). Community perceptions of health insurance and their preferred design features: implications for the design of universal health coverage reforms in Kenya. BMC Health Services Research, 13(474), 1-12.

Nachar, N. (2008). The Mann- Whitney U:A Test for Assessing Whether Two Independent Samples Come from the Same Distribution. Tutorials in Quantitative Methods for Psychology. $4(1), 13-20$.

Ndomba, T., \& Maluka, S. (2019). Uptake of community health fund: why is Mtwara District lagging behind? Retrieved from https://doi.org/10.35500/jghs.2019.1.e50

Pallant, J. (2007). Statistical Package for Social Sciences (SPSS) Survival Manual: A step-by-step Guide to Data Analysis Using SPSS for Windows $3^{\text {rd }}$ Edition. Open University Press. Berkshire. 133pp.

Temba, M. F., \& Leonard, W. (2013). Social security right in Tanzania: An overview of the forms, scope and the way forward. Journal of Policy and Leadership, 2(1), 136- 152.

Turkson, P. K. (2009). Perceived quality of health care delivery in a rural District of Ghana. Ghana Medical Journal, 42(2), 123.

URT. (1977). The private hospitals regulation act No. 6 of 1977 in Dar es salaam Tanzania. $31 \mathrm{pp}$.

URT. (2001). The community health fund act, no.1 of 2001.

URT. (2008). Report on medicines coverage and health insurance programs survey in Tanzania. Ministry of Health and Social Services, Dar es salaam Tanzania. 33pp.

URT. (2015). Annual health sector performance profile 2014/2015, Dar es salaam Tanzania. $128 \mathrm{pp}$.

URT. (2015). Prospectus for sustainable health financing in Tanzania: Dar es salaam. 27pp.

Waheke, J. W. (2015). Effects and challenges of Community Health Fund on accessibility to health care services: a case of Songea district, Tanzania. A Dissertation Submitted in Partial Fulfillment of the Requirement for Master Degree of Health Systems Management (MHSM) of Mzumbe University Morogoro Tanzania: 69pp.

Winani, S. C. (2015). Community Health Fund Scheme in Tanzania: Exploration of its challenges and opportunities in contribution towards universal Health coverage. A 


\section{Macrothink}

Journal of Public Administration and Governance ISSN 2161-7104 2020, Vol. 10, No. 2

Dissertation Submitted in Partial Fulfilment of the Requirement for Master Degree of Public Health (MPH) of Vrije University, Amsterdam, Netherland: 41pp.

WHO. (2003). Community based health insurance schemes in developing countries: facts, problems, and perspectives. Discussion paper number 1-2003 in Geneva. 39pp.

\section{Copyright Disclaimer}

Copyright for this article is retained by the author(s), with first publication rights granted to the journal.

This is an open-access article distributed under the terms and conditions of the Creative Commons Attribution license (http://creativecommons.org/licenses/by/4.0/). 